\title{
Fatigue Crack Growth in Lithium Hydride
}

Thomas E. Healy

(M.S. Thesis)

September 1, 1993 


\section{DISCLAIMER}

This document was prepared as an account of work sponsored by an agency of the United States Government. Neither the United States Government nor the University of California nor any of their employees, makes any warranty, express or implied, or assumes any legal liability or responsibility for the accuracy, completeness, or usefulness of any information, apparatus, product, or process disclosed, or represents that its use would not infringe privately owned rights. Reference herein to any specific commercial product, process, or service by trade name, trademark, manufacturer, or otherwise, does not necessarily constitute or imply its endorsement, recommendation, or favoring by the United States Government or the University of California. The views and opinions of authors expressed herein do not necessarily state or reflect those of the United States Government or the University of California, and shall not be used for advertising or product endorsement purposes.

This report has been reproduced directly from the best available copy.

Available to DOE and DOE contractors from the

Office of Scientific and Technical Information

P.O. Box 62, Oak Ridge, TN 37831

Prices available from (615) 576-8401, FTS 626-8401

Available to the public from the

National Technical Information Service

U.S. Department of Commerce

5285 Port Royal Rd.

Springfield, VA 22161

Work performed under the auspices of the U.S. Department of Energy by Lawrence Livermore National Laboratory under Contract W-7405-ENG-48. 


\section{Fatigue Crack Growth in Lithium Hydride}

Thomas E. Healy

(M.S. Thesis)

Manuscript date: September 1, 1993

\section{LAWRENCE LIVERMORE NATIONAL LABORATORY}

University of California - Livermore, California • 94551 


\section{DISCLAIMER}

Portions of this document may be illegible in electronic image products. Images are produced from the best available original document. 
Fatigue Crack Growth in Lithium Hydride

By

THOMAS E. HEALY

B.S. (California Polytechnic State University, San Luis Obispo) 1986

\section{THESIS}

Submitted in partial satisfaction of the requirements for the degree of

MASTER OF SCIENCE

in

MECHANICAL ENGINEERING

in the

OFFICE OF GRADUATE STUDIES

of the

UNIVERSITY OF CALIFORNIA

DAVIS

Approved:
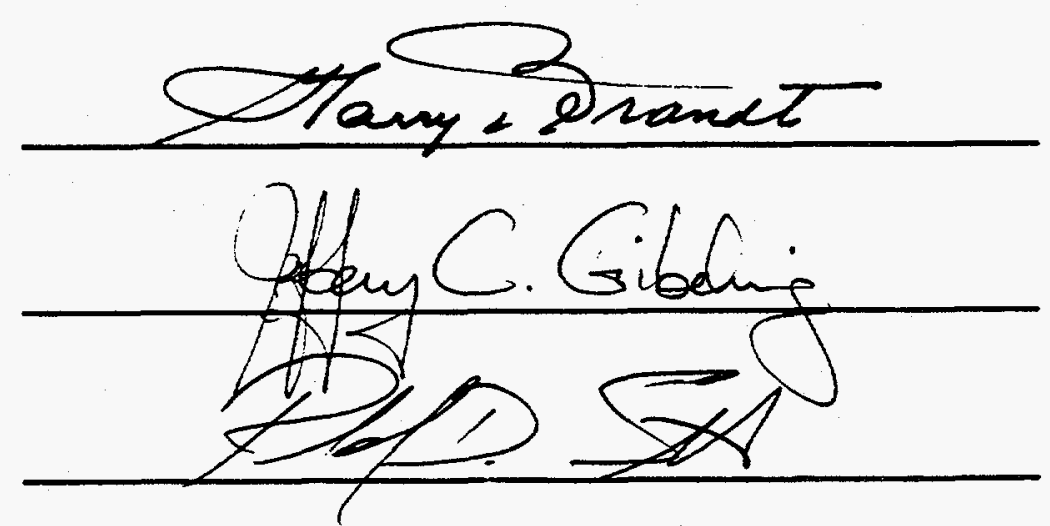

Committee in Charge

1993 
Table of Contents

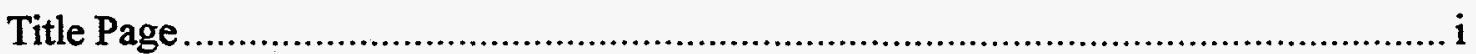

Table of Contents .................................................................................... ii

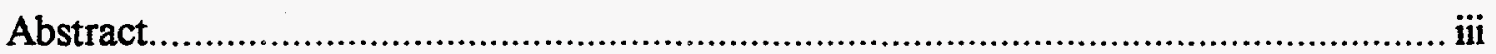

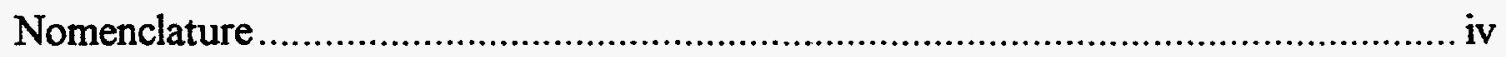

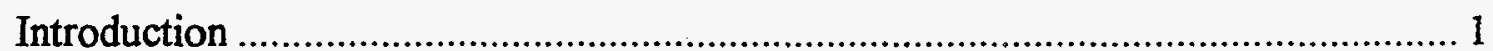

Fracture Mechanics and Fatigue Crack Growth............................................. 2

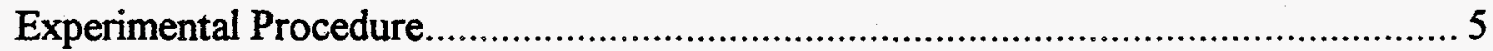

Test Specimen Material......................................................................... 5

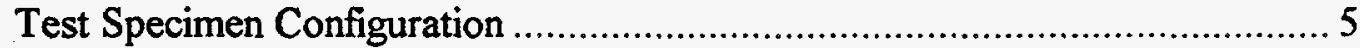

Crack Length and Crack Closure Measurement ...................................6 6

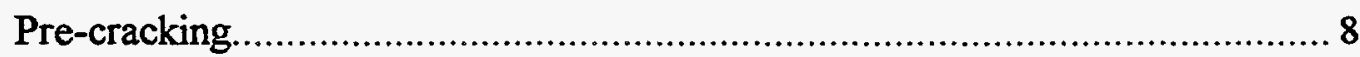

Loading Technique ...................................................................... 8

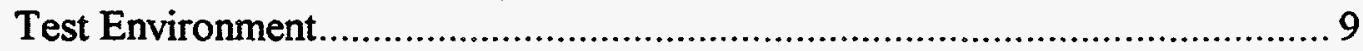

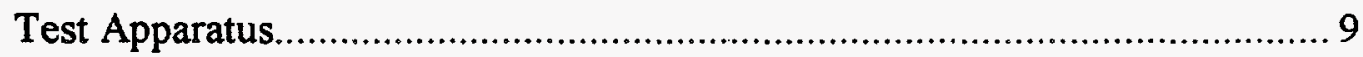

Data Reduction ............................................................................. 10

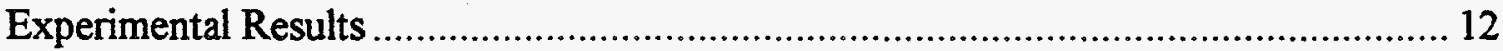

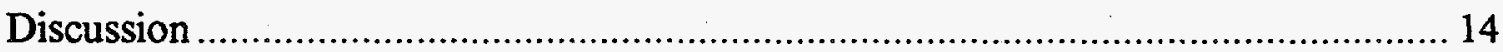

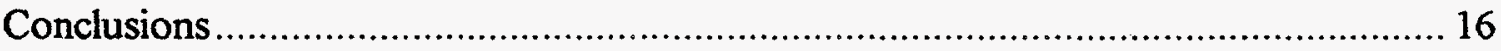

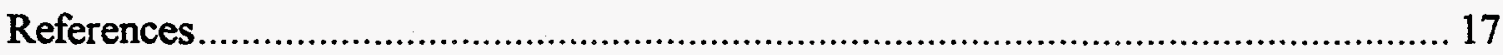

Appendix A - Crack Extension Stability ...................................................... 20

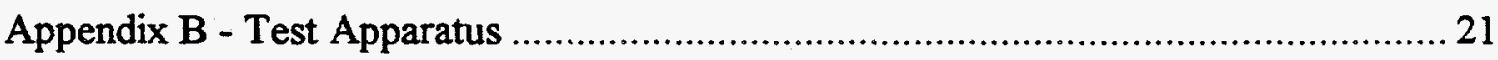

Appendix C - Fatigue Crack Growth Data ............................................. 23 


\begin{abstract}
Subcritical fatigue crack growth, from cyclic tensile loading, was demonstrated in warm pressed polycrystalline lithium hydride. Experiments were performed with cyclic tensiontension crack opening (mode I) loads applied to a pre-cracked compact type specimen in an argon environment at a temperature of $21^{\circ} \mathrm{C}\left(70^{\circ} \mathrm{F}\right)$. The fatigue crack growth was found to occur between $7.56 \times 10^{-11} \mathrm{~m} /$ cycle $\left(2.98 \times 10^{-9} \mathrm{in} /\right.$ cycle $)$ and $2.35 \times 10^{-8} \mathrm{~m} /$ cycle $\left(9.24 \times 10^{-7} \mathrm{in} / \mathrm{cycle}\right)$ for a range of stress intensity factors between $1.04 \mathrm{MPa} \cdot \sqrt{\mathrm{m}}$ $(0.95 \mathrm{ksi} \cdot \sqrt{\mathrm{in}})$ and $1.49 \mathrm{MPa} \cdot \sqrt{\mathrm{m}}(1.36 \mathrm{ksi} \cdot \sqrt{\mathrm{in}})$. The rate of fatigue crack growth from cyclic tensile loading was found to be in excess of crack growth from sustained loading at an equivalent stress intensity factor. Furthermore, a fatigue threshold was not evident from the acquired data.
\end{abstract}




\section{Nomenclature}

a crack length, a linear measure of a principal planar dimension of the crack measured from the load-line to the tip of the crack.

$\Delta \mathrm{a} \quad$ crack extension, an increase in crack length.

B specimen thickness.

C normalized K-gradient, the fractional rate of change of $\mathrm{K}$ with increasing crack length.

$\mathrm{C}, \mathrm{m}$ constants in the crack growth relationship defined by da/dN $=\mathrm{C}(\Delta \mathrm{K})^{\mathrm{m}}$.

C(T) compact type specimen, as defined in ASTM E647-91.

$\mathrm{da} / \mathrm{dN}$ fatigue crack growth rate, the rate of crack extension caused by fatigue loading and expressed in terms of average crack extension per cycle.

E Young's modulus.

G energy release rate (or crack extension force), the elastic energy per unit of new separation area that is made available at the front of an ideal crack in an elastic solid during a virtual increment of forward crack extension.

K stress intensity factor, a measure of the stress and deformation field that surrounds a crack-tip.

$\mathrm{K}_{\mathrm{cl}}$ closure stress intensity factor, the stress intensity where during the unloading portion of a fatigue cycle the opposing crack faces near the tip of the crack come into contact before the minimum load of the cycle is reached.

$\mathrm{K}_{\mathrm{IC}}$ plane strain fracture toughness, the crack extension resistance under conditions of crack-tip plane strain.

$\mathrm{K}_{\max }$ highest algebraic value of the stress intensity factor in a cycle, the value corresponding to the maximum load $\left(\mathrm{P}_{\max }\right)$.

$\mathrm{K}_{\min }$ lowest algebraic value of the stress intensity factor in a cycle, the value corresponding to the minimum load $\left(P_{\min }\right)$ when the load ratio $(R)$ is greater than zero and is set equal to zero when $R$ is less than or equal to zero.

$\Delta \mathrm{K} \quad$ range of stress intensity factors, the algebraic difference between the maximum and the minimum stress intensity factor in a cycle, $\Delta \mathrm{K}=\mathrm{K}_{\max }-\mathrm{K}_{\min }$. 
$\Delta \mathrm{K}_{\text {th }}$ fatigue threshold range of stress intensity factors, the value below which crack growth is assumed negligible. For the purpose of this investigation, the fatigue threshold crack growth rate was defined as da/dN $=1.00 \times 10^{-10} \mathrm{~m} /$ cycle $\left(3.94 \times 10^{-9} \mathrm{in} /\right.$ cycle $)$.

N number of elapsed load cycles.

P load, the force applied to the test specimen.

$\mathbf{P}_{\max }$ load having the highest algebraic value in a cycle, tensile load being considered positive and compressive load negative.

$\mathbf{P}_{\min }$ load having the lowest algebraic value in a cycle, tensile load being considered positive and compressive load negative.

$\Delta P \quad$ range of loads, the algebraic difference between the maximum and minimum loads in one cycle, $\Delta \mathrm{P}=\mathrm{P}_{\max }-\mathrm{P}_{\min }$.

Q a dimensionless parameter which depends on the specimen geometry.

$\mathbf{R}$ load ratio, the algebraic ratio of the minimum to maximum load in a cycle, $\mathbf{R}=\mathbf{P}_{\min } \mathbf{P}_{\max }$

W specimen width, a physical dimension on the test specimen measured from the load-line to the back edge of the specimen.

$\sigma \quad$ applied stress. 


\section{Introduction}

Lithium hydride is used as a fuel for thermonuclear devices. To insure satisfactory performance of these devices, the lithium hydride components must maintain their physical shape and structural integrity when exposed to vibration during their lifetime. Therefore, the ability to predict the structural survivability of a lithium hydride component in a vibration environment is desired. Accordingly, the motivation for this investigation was to provide a portion of the information necessary to predict this survivability.

Experience has demonstrated that a crack in lithium hydride traverses a structural component at a rate proportional to the amplitude of the vibration environment [1]. Therefore, subcritical fatigue crack growth was reasoned to occur in lithium hydride. Accordingly, this investigation was conducted to confirm the existence of subcritical fatigue crack growth in warm pressed polycrystalline lithium hydride; and to quantify the rate of crack growth in a cyclic tensile loading environment $(\mathrm{da} / \mathrm{dN})$ as a function of the crack-tip range of stress intensity factors $(\Delta \mathrm{K})$.

The testing was accomplished by loading a pre-cracked compact type specimen, manufactured from warm pressed polycrystalline lithium hydride, with cyclic tensiontension crack opening (mode I) loads, in an argon environment at ambient room temperature. 


\section{Fracture Mechanics and Fatigue Crack Growth}

Traditionally, a stress-life approach has been used to estimate the structural degradation of a component exposed to cyclic loading. In recent years, a fracture mechanics approach has gained popularity as a method to estimate crack growth behavior in a cyclic loading environment. The fracture mechanics approach utilizes the stress intensity factor as a method of quantifying the driving force for crack advance. The stress intensity factor quantifies the stress and deformation field that surrounds a crack-tip, rather than the stress at the crack-tip. The stress intensity factor $(\mathrm{K})$ depends on the crack length (a), the applied stress $(\sigma)$, and the specimen geometry $(Q)$ in the following way [2]:

$$
\mathrm{K}=\mathrm{Q} \sigma \sqrt{\pi \mathrm{a}}
$$

The fracture mechanics approach is based on the theory of linear elasticity and is valid provided that gross yielding does not occur [3]. Under sustained loading and plane strain conditions, when the stress intensity factor reaches a critical value $\mathrm{K}_{\mathrm{IC}}$ (also known as the plane strain fracture toughness of the material), rapid crack advance occurs. However, subcritical crack growth can occur, at values less than $\mathrm{K}_{\mathrm{IC}}$, in a cyclic loading environment (or by other mechanisms such as stress corrosion).

Historically, Griffith [4] is credited with developing the foundation of the study of fracture. Griffith's theory equates the release of strain energy associated with incremental crack growth to the energy required to create the new surfaces (surface energy). If the strain energy is sufficient, the crack will propagate; if it is not sufficient, the stress in the material will simply increase. Griffith first applied his theory to the fracture of glass and obtained crude agreement with his test results [5]. Later, Irwin [6] introduced the concept of the stress intensity factor (K). Linear Elastic Fracture Mechanics (LEFM), as it currently exists, is primarily based on the stress intensity factor. LEFM has been used to evaluate fracture in metals, ceramics, rock, glass, polymers, and organic materiais. 
Using the stress intensity factor provides the benefit of similitude in evaluating cracks of different size from bodies of different size and shape. If the stress intensities for two different cracks are equal, there is exact similitude. Accordingly, the two cracks should respond in the same manner.

For crack growth from cyclical loading, Paris [7] related the rate of crack growth (da/dN) to the range of stress intensity factors encountered in the cyclic loading environment $\left(\Delta K=K_{\max }-K_{\min }\right)$, and material constants $(C, m)$ in the following way:

$$
\frac{\mathrm{da}}{\mathrm{dN}}=\mathrm{C}(\Delta \mathrm{K})^{\mathrm{m}}
$$

The range of stress intensity factors is used to quantify the driving force for crack advance under cyclic loading. The driving force can be reduced below the applied $\Delta \mathrm{K}$ by premature contact between the faces of the crack during unloading (crack closure). Crack closure is produced by a variety of mechanisms and is often quantified by determining a closure stress intensity $\mathrm{K}_{\mathrm{cl}}$ which replaces the $\mathrm{K}_{\min }$ in the $\Delta \mathrm{K}$ expression.

The functional relationship between the fatigue crack growth rate and the range of stress intensity factors has been successfully applied to metals, ceramics, granite, and other materials. The fatigue crack growth behavior of ceramics is of particular interest because of the similarities between ceramics and warm pressed lithium hydride. As with many ceramics, lithium hydride has strong atomic bonds. Hence, both ceramics and lithium hydride are prone to brittle fracture and low values of fracture toughness $\left(\mathrm{K}_{\mathrm{IC}}\right)$. In contrast, most metals are able to deform and absorb energy during crack propagation. Therefore, metals are generally prone to a more ductile fracture and higher values of fracture toughness.

A long standing viewpoint has been that ceramic materials are not subject to significant degradation from cyclic loading [8]. This view was based mainly on the negligible amount of plastic deformation capacity believed to be available at the crack-tip within the ceramic 
microstructures. The conclusion was supported by observations that cyclic crack growth in $\mathrm{Si}_{3} \mathrm{~N}_{4}$, porcelain, and glass, was a result of environmentally induced subcritical crack growth (stress corrosion cracking) under varying load $[9,10,11]$. Accordingly, environmentally induced subcritical crack growth from sustained load received the majority of attention $[12,13]$ in the early years of study. However, recent studies have demonstrated that fatigue damage does occur in cyclic loading of ceramics. In the late 1980 's, fatigue crack growth was demonstrated for ceramics in cyclic compressive loads of notched specimens $[14,15]$. In these studies, the primary mechanism for crack growth was attributed to the residual tensile stresses created at the notch-tip upon unloading from compression. In the late 1980's and early 1990's, fatigue crack growth was demonstrated for ceramics in cyclic tension-tension loading of compact tension specimens $[16,17,18,19,20]$. In these studies, the rate of crack growth from cyclic loading was found to exceed that from sustained loading. Therefore, the crack growth was demonstrated to be a genuine fatigue phenomena and not a direct cyclic manifestation of crack growth from sustained loads. Of particular interest is the successful demonstration of fatigue crack growth from tensile loading in pyrolytic carbon-coated graphite [21] because of its similar fracture toughness to lithium hydride. In this study, the subcritical crack velocities were found to exceed those measured from equivalent sustained loads and to occur at $45 \%$ lower stress intensity factor levels. The crack growth in these cyclic tensile loaded specimens was suggested to be a result of mechanisms which damage the microstructure ahead of the crack-tip, as well as those which do not necessarily differ from the crack advance mechanisms found in fracture from sustained loading, but enhance the crack driving force by reducing the crack-tip shielding. 


\section{Experimental Procedure}

\section{Test Specimen Material}

The material is identified as warm pressed polycrystalline lithium hydride. It is manufactured by Martin Marietta Energy Systems, Inc., Y-12 Plant, located in Oak Ridge Tennessee. Solid billets are consolidated from powder using warm isostatic pressing methods to achieve a material density which is $99.5 \%$ of theoretical. Previous testing has been performed to determine engineering material properties $[22,23]$. The elastic modulus ranges from $71.0 \mathrm{GPa}(10.3 \mathrm{Mpsi})$ to $81.3 \mathrm{GPa}(11.8 \mathrm{Mpsi})$. The Poisson's ratio is 0.08 . The ultimate tensile strength ranges from $16.8 \mathrm{MPa}$ (2437 psi) to $54.9 \mathrm{MPa}$ (7962 psi). The lower values of tensile strength, $16.8 \mathrm{MPa}$ (2437 psi) to $39.6 \mathrm{MPa}$ (5743 psi), are believed to result from machining surface damage of the specimens. The remaining distribution of tensile strength, $39.6 \mathrm{MPa}$ (5743 psi) to $54.9 \mathrm{MPa}$ (7962 psi), can be explained using Weibull's two-parameter statistical distribution which accounts for the size of the specimen as well as the stress distribution [24]. The short rod plane strain fracture toughness $\left(\mathrm{K}_{\mathrm{IC}}\right)$ ranges from $0.99 \mathrm{MPa} \cdot \sqrt{\mathrm{m}}(0.90 \mathrm{ksi} \cdot \sqrt{\text { in }})$ to $1.54 \mathrm{MPa} \cdot \sqrt{\mathrm{m}}$ $(1.40 \mathrm{ksi} \cdot \sqrt{\mathrm{in}})$ [25].

The test specimens were fabricated from material which is the same as that used in production devices. The specimens were machined to shape in a dry environment (less than $10 \%$ relative humidity) and were further dried in a vacuum oven for approximately one week to ensure their similarity in moisture content.

\section{Test Specimen Configuration}

Cyclic fatigue crack growth studies were performed with a single edge-notched compact type $C(T)$ specimen containing a through-thickness fatigue pre-crack. The specimen was designed according to the guidelines in ASTM E647-91 "Standard Test Method for Measurement of Fatigue Crack Growth Rates" [26]. The specimen dimensions, as shown in Fig. 1, are $0.127 \mathrm{~m}$ ( 5.0 inches) long by $0.0254 \mathrm{~m}$ ( 1.0 inch) thick by $0.1219 \mathrm{~m}$ (4.8 inches) in height. The thickness of the specimen was chosen to provide a dimension 
which was large compared to the material grain size (the material grain size can be as large as $508 \mu \mathrm{m}$, providing a 50 to 1 thickness to grain size ratio). The length and height of the specimen were predicated on the guidelines in ASTM E647-91. The length of the machined portion of the crack, $0.0864 \mathrm{~m}$ (3.4 inches), was defined such that, for the calculated specimen compliance and the measured test machine axial compliance, an increase in the system energy would be required for further crack extension. More details of the crack extension stability are provided in Appendix A. A wedge-shaped notch was machined into the specimen to facilitate the fatigue pre-cracking. Crack growth through the wedge-shaped starter notch was not used for evaluation of the fatigue crack growth rate. The wedge-shape was asymmetric, differing from the Chevron notch, so that the fatigue pre-cracking could be monitored from one face of the specimen.

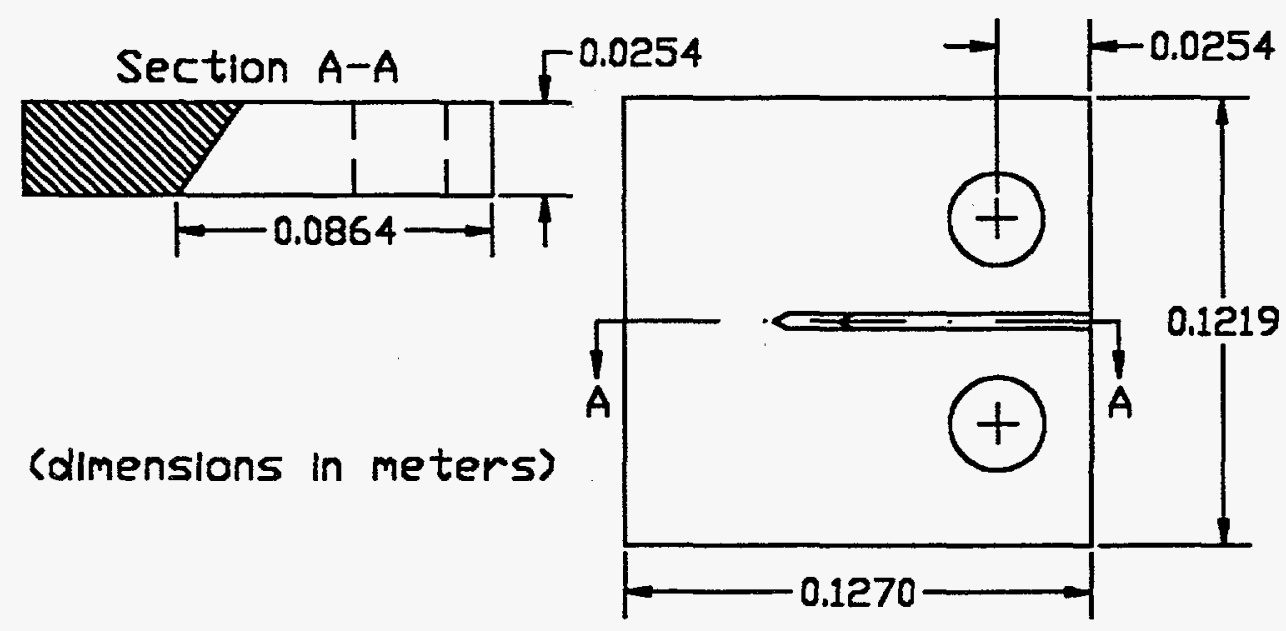

Fig. 1. Compact type specimen, designed according to the guidelines in ASTM E647-91.

\section{Crack Length and Crack Closure Measurement}

Compliance techniques were used to measure the crack length in the specimen. The displacement used was that obtained from a displacement transducer mounted near the mouth of the crack. The phase of the load and displacement signals were adjusted to insure their simultaneity. The signals were then digitized and used by a computer system 
to evaluate the compliance. The compliance was determined over the portion of the loaddisplacement curve above the crack closure induced non-linearity and below the upper $5 \%$. The upper $5 \%$ of the load-displacement curve was disregarded to minimize errors which might have occurred as a result of friction in the pin to clevis interface.

The compliance technique of indirectly measuring the crack length was found to be temporarily unstable following an increase in load. More specifically, when the load was increased, for the purpose of providing a larger $\Delta \mathrm{K}$, the measurement of the crack length would reduce by as much as $0.1 \mathrm{~mm}(0.004 \mathrm{inch})$. Thereafter, the measurement of the crack length would restabilize and slowly return to the true value (as optically measured). The instability was quantified by using an aluminum specimen having a machined slot to serve as a known and unchanging crack. The aluminum specimen was loaded in cyclic tension with the same load and displacement range used for the lithium hydride specimen. Furthermore, the load and displacement data from the aluminum specimen was acquired and reduced using the same method as for the lithium hydride specimen. The data from the aluminum specimen illustrated that the crack length measurement instability contributed to questionable fatigue crack growth measurements for as many as 150,000 cycles following an increase in load. In particular, following a load increase, the measured crack length would abruptly reduce and then slowly return to the true crack length. Since the data acquisition software could not differentiate between a true change in crack length and a fictitious change resulting from a load increase, fatigue crack growth rates were calculated for all of the data. Therefore, the validity of the fatigue crack growth data acquired in less than 150,000 cycles following a load increase was considered questionable.

Optical techniques, with a traveling microscope, were used to verify the compliance crack length measurement. Only the initial crack length was verified for the first specimen. However, the initial and final crack lengths were verified for the second specimen. The 
optically measured crack length was found to be $9 \%$ longer than the length measured using compliance.

The fatigue crack closure was measured using the same load and displacement signals as used for the crack length measurement. The crack closure measurement was accomplished using a correlation technique to identify the load at which the loaddisplacement curve transitions from linear to non-linear. The loading portion of the cycle was used for each determination so that any hysteresis would not effect the measurement. The correlation technique involved fitting a straight line to the upper $20 \%$ of the loaddisplacement data using a least squares method. Then, successive least squares fits were made, incorporating consecutive load-displacement data points. A correlation coefficient was calculated for each successive straight line fit to provide a measure of the correlation between the data and the straight line. The load at which crack closure occurred was associated with that data point which, when incorporated into the least squares fit, caused the correlation coefficient to decrease from the previous coefficients.

\section{Pre-cracking}

Owing to the brittleness of the lithium hydride, the load required to initiate the crack was anticipated to be larger than the load required to advance the crack just after initiation. Since an excessive load could result in abrupt crack extension, and possibly complete failure, crack initiation was accomplished by growing a crack out of a wedge-shaped starter notch using cyclic tensile-tensile loading under displacement control. However, the

second specimen was pre-cracked by an inadvertent compressive load. While the compression of the specimen was not intended, it appeared to produce an acceptable precrack and was therefore used for further testing.

\section{Loading Technique}

The specimens were cycled according to the guidelines in ASTM E647-91 "Standard Test Method for Measurement of Fatigue Crack Growth Rates" [26]. A cyclic sinusoidal loading frequency of $20 \mathrm{~Hz}$ was used with a constant load ratio $\left(\mathrm{R}=\mathrm{P}_{\min } / \mathrm{P}_{\max }\right)$ of 0.1 . 
The range of stress intensity factors was increased periodically, and a K-decreasing loading technique was used between increases to acquire data over a range of fatigue crack growth rates. The rate of change in the stress intensity factor during K-decreasing loading was predicated on the initial values of crack length $\left(\mathrm{a}_{\mathrm{o}}\right)$ and the range of stress intensity factors $\left(\Delta \mathrm{K}_{\mathrm{o}}\right)$, the instantaneous crack length (a), and a constant normalized $\mathrm{K}$-gradient (C) of $\pm 0.08 \mathrm{~mm}^{-1}\left( \pm 2.0 \mathrm{in}^{-1}\right)$ in the following way [26]:

$$
\begin{aligned}
& \Delta K=\Delta K_{0} e^{C\left(a-a_{o}\right)} \\
& \text { where: } C=\frac{1}{K} \cdot \frac{d K}{d a}
\end{aligned}
$$

Loading of the specimen following the pre-cracking was performed under computer control.

\section{$\underline{\text { Test Environment }}$}

The tests were performed in an argon gas environment a temperature of $21^{\circ} \mathrm{C}\left(70^{\circ} \mathrm{F}\right)$.

\section{Test Apparatus}

Fig. 2 shows the experimental equipment used for this investigation. The tests were conducted using an electro-servo-hydraulic test system. A computer was interfaced to the system for test control and data acquisition. The K-decreasing loading was performed under stress intensity factor control with the use of a strain gaged load cell and a compliance measured crack length. The pre-cracking was performed under displacement control with the use of a Linear Variable Differential Transformer displacement transducer mounted on the specimen. The displacement transducer was also used in the compliance measurement of the crack length and for evaluating crack closure. The loading fixtures were designed to minimize non-axial loading while providing a high axial stiffness. Because lithium hydride reacts with moisture in the air, a low humidity environment was provided with an environmental enclosure surrounding the test unit. More details of the test apparatus are provided in Appendix B. 


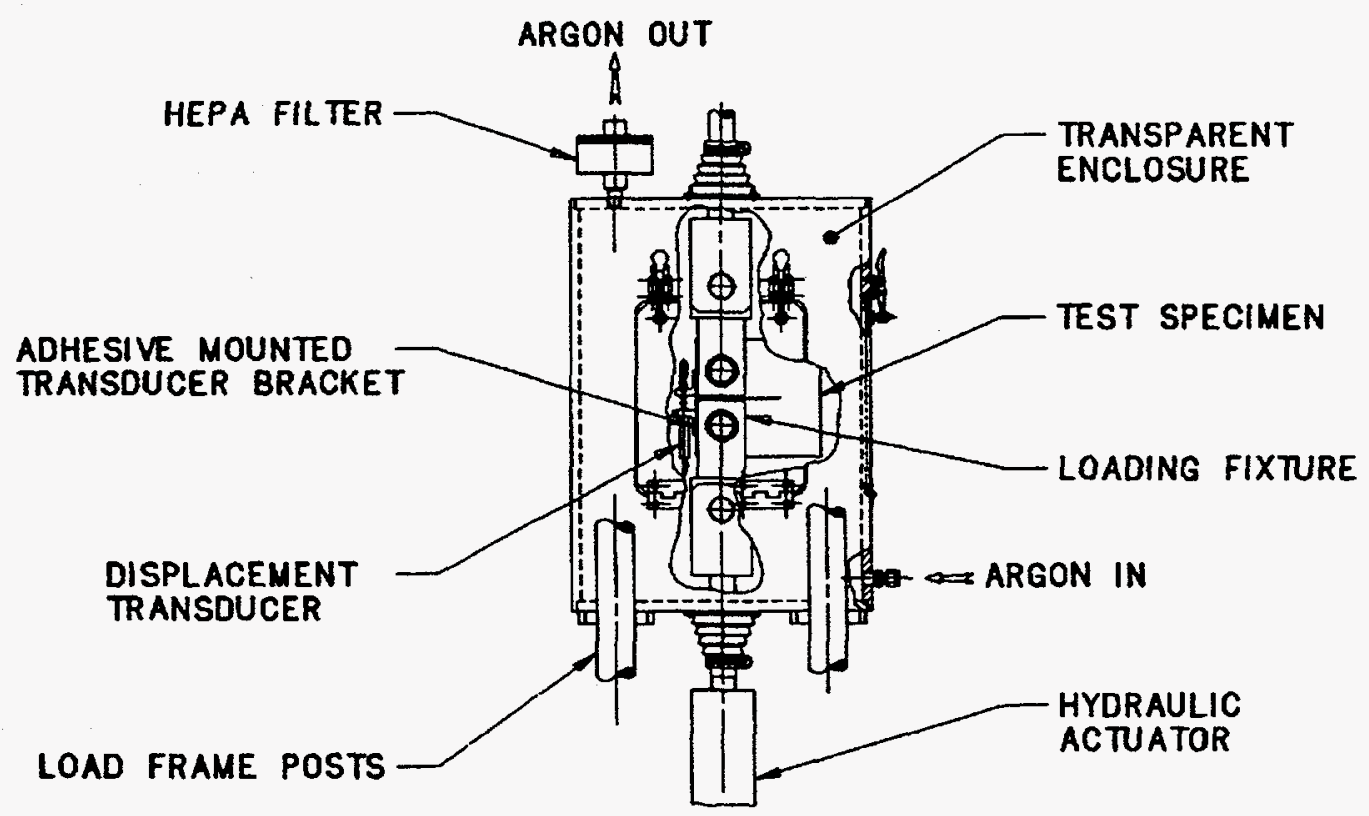

Fig. 2. The test set-up was designed to minimize non-axial loading while providing a high axial stiffness, and to maintain an argon environment around the lithium hydride.

\section{Data Reduction}

The fatigue crack growth rate was expressed on a log-log plot of $\mathrm{da} / \mathrm{dN}$ as a function of the crack-tip range of stress intensity factors $(\Delta \mathrm{K})$. The stress intensity factors were calculated from an expression based on linear elastic stress analysis. For the compact type specimen, the range of stress intensity factors was calculated as $\Delta \mathrm{K}=\mathrm{K}_{\max }-\mathrm{K}_{\min }$ where the stress intensity factor $(\mathrm{K})$ is related to the load $(\mathrm{P})$, the specimen thickness $(\mathrm{B})$, the specimen width (W), and the crack length (a) in the following way:

$$
K=\frac{P}{B W^{1 / 2}} \frac{\left(2+\frac{a}{w}\right)}{\left(1-\frac{a}{w}\right)^{3 / 2}}\left[0.886+4.64 \frac{a}{W}-13.32\left(\frac{a}{W}\right)^{2}+14.72\left(\frac{a}{W}\right)^{3}-5.6\left(\frac{a}{W}\right)^{4}\right]
$$

Equation 4 is considered to be accurate within $\pm 0.5 \%$ over the range of a/W from 0.2 to $1.0[26]$. 
The rate of fatigue crack growth $(\mathrm{da} / \mathrm{dN})$ was determined from the crack length versus elapsed cycles using the incremental polynomial method [26]. The incremental polynomial method involved fitting a second order polynomial to sets of successive "a" versus "N" data points, evaluating the derivative of the polynomial, and correlating it to the range of stress intensities. 


\section{Experimental Results}

Subcritical fatigue crack growth, from cyclic tensile loading, was demonstrated in warm pressed polycrystalline lithium hydride.

The fatigue crack growth was founc to occur between $7.56 \times 10^{-11} \mathrm{~m} /$ cycle $\left(2.98 \times 10^{-9} \mathrm{in} /\right.$ cycle $)$ and $2.35 \times 10^{-8} \mathrm{~m} /$ cycle $\left(9.24 \times 10^{-7} \mathrm{in} /\right.$ cycle $)$ for a range of stress intensity factors of $1.04 \mathrm{MPa} \cdot \sqrt{\mathrm{m}}(0.95 \mathrm{ksi} \cdot \sqrt{\mathrm{in}})$ to $1.49 \mathrm{MPa} \cdot \sqrt{\mathrm{m}}(1.36 \mathrm{ksi} \cdot \sqrt{\mathrm{in}})$. The results from two test specimens are plotted in Fig. 3 with the fatigue crack growth rate $(\mathrm{da} / \mathrm{dN})$ represented as a function of the range of stress intensity factors $(\Delta \mathrm{K})$. The fatigue crack growth data is also provided in Appendix C. The data points whose validity is questionable, as discussed in the Crack Length and Crack Closure Measurement section, are also illustrated in Fig. 3. The rate of fatigue crack growth is conventionally related to the range of stress intensity factors encountered in the cyclic loading environment using the Paris Law relationship. However, the scatter of the data illustrated in Fig. 3 does not necessarily lend itself to a relationship such as the Paris Law. Nevertheless, to provide a basis for comparison of the test data to the Paris Law relationship for other materials, the fatigue crack growth rate was correlated to the range of stress intensity factors to provide a power-law relationship of $\mathrm{da} / \mathrm{dN}=4.28 \times 10^{-11}(\Delta \mathrm{K})^{14}$ for units of $\mathrm{m} /$ cycle, MPa $\sqrt{\mathrm{m}}$ $\left(\mathrm{da} / \mathrm{dN}=6.54 \times 10^{-9}(\Delta \mathrm{K})^{14}\right.$ for units of in/cycle, $\left.\mathrm{ksi} \cdot \sqrt{\mathrm{in}}\right)$. The power-law relationship, as denoted by the solid line in Fig. 3, was predicated on the data point having the lowest fatigue crack growth rate and the data point having the median fatigue crack growth rate of those data points from specimen No. 1 . 


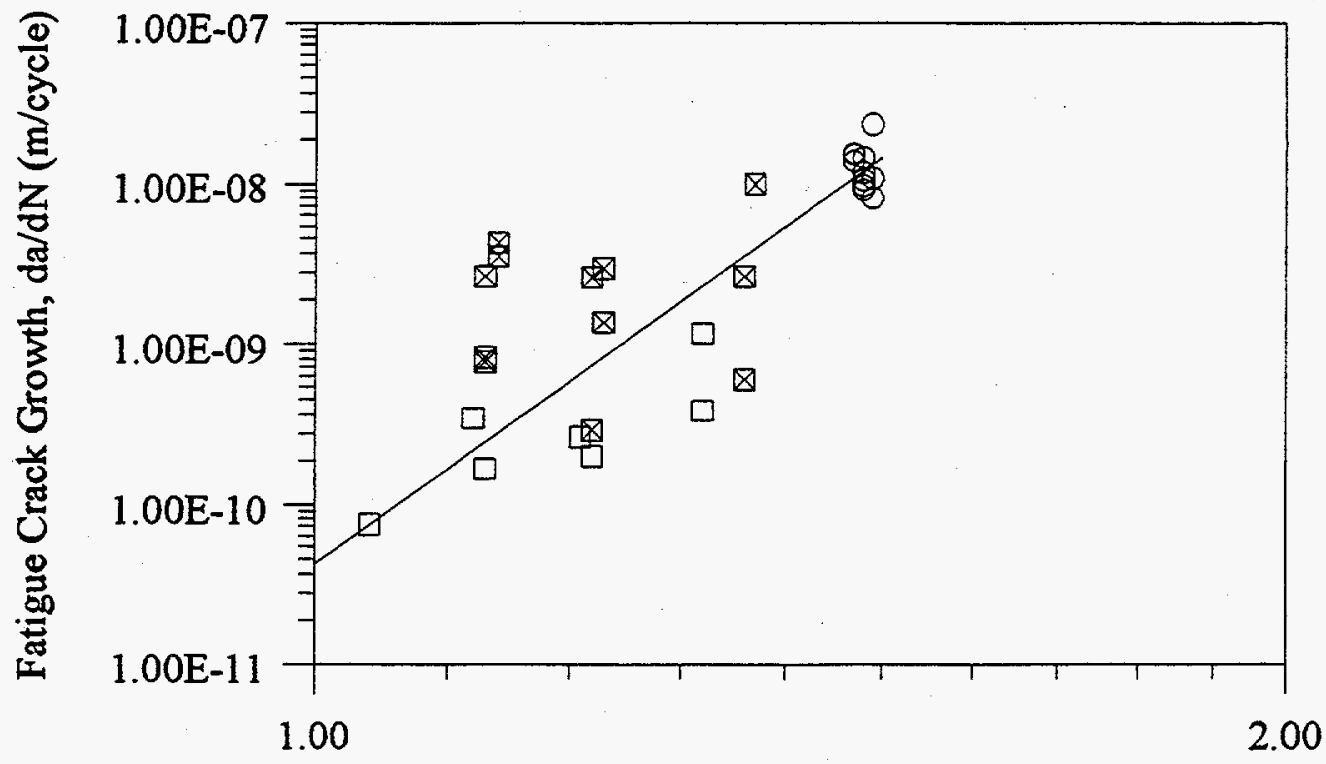

Stress Intensity Factor Range, Delta-K $\left(\mathrm{MPa}^{\wedge} \mathrm{m}^{\wedge} 1 / 2\right)$
Specimen No. 1 data
Specimen No. 2 data
$\otimes$ Specimen No. 2 data (questionable)
- Paris Law

Fig. 3. Cyclic loading at $20 \mathrm{~Hz}$ and $\mathrm{R}=0.10$ resulted in fatigue crack growth rates between $7.56 \times 10^{-11} \mathrm{~m} /$ cycle and $2.35 \times 10^{-8} \mathrm{~m} /$ cycle for a range of stress intensity factors of $1.04 \mathrm{MPa} \cdot \sqrt{\mathrm{m}}$ to $1.49 \mathrm{MPa} \cdot \sqrt{\mathrm{m}}$.

A fatigue threshold was not evident from the acquired data. However, for the purpose of this investigation, the fatigue threshold range of stress intensity factors $\left(\Delta \mathrm{K}_{\mathrm{th}}\right)$ was defined as that value below which the crack growth rate was less than $1.00 \times 10^{-10} \mathrm{~m} /$ cycle $\left(3.94 \times 10^{-9} \mathrm{in} /\right.$ cycle $)$ [26]. The $\Delta \mathrm{K}_{\mathrm{th}}$ was found to be $1.05 \mathrm{MPa} \cdot \sqrt{\mathrm{m}}(0.96 \mathrm{ksi} \cdot \sqrt{\mathrm{in}})$. 


\section{Discussion}

The research presented here represents the first known evidence of the fatigue crack growth behavior in warm pressed polycrystalline lithium hydride. The existence of cyclic fatigue crack growth phenomena in lithium hydride runs counter to the belief that brittle ceramic-like materials are not susceptible to subcritical fracture by cyclic fatigue [27].

Using fatigue crack growth data from two test specimens, a conventional power-law relationship of the form da/dN $=C(\Delta K)^{\mathrm{m}}$ was calculated. The exponent of the power-law relationship, $\mathrm{m}=14$, was found to be in excess of that for most metals (in the 2 to 4 range [28]) and more characteristic of that for brittle ceramics (ranging from 10 to 100 [20]). The large exponent illustrates the high sensitivity of the rate of fatigue crack growth $(\mathrm{da} / \mathrm{dN})$ to the range of stress intensity factors $(\Delta \mathrm{K})$.

The fatigue crack growth data demonstrated evidence of crack closure. The crack closure was possibly a result of wedging by fracture surface asperities. The ratio of the crack closure stress intensity factor to the maximum stress intensity factor $\left(\mathrm{K}_{\mathrm{cl}} / \mathrm{K}_{\max }\right)$ was estimated to range from 0.24 to 0.29 for the acquired data.

An expected question resulting from a fatigue crack growth test of brittle material, such as performed here, is whether the observed crack growth was a genuine fatigue crack growth phenomena or a result of environmentally induced subcritical crack growth from varying load. To address this issue, a 22 hour sustained load test was performed with a $\mathrm{K}_{\max }=1.60 \mathrm{MPa} \cdot \sqrt{\mathrm{m}}(1.46 \mathrm{ksi} \cdot \sqrt{\mathrm{in}})$. While the sustained load test produced no detectable crack extension, the range of stress intensity factors for a $\mathrm{K}_{\max }$ of this magnitude in a cyclic load test, having a load ratio of 0.1 . would result in an obvious crack extension. Therefore, the observed cyclic crack growth in this investigation was believed to be a result of the cyclic loading.

The mechanisms of cyclic crack advance in metals are typically attributed to dislocation plasticity. The limited crack-tip plasticity in ceramics has encouraged a viewpoint that these materials were not prone to significant degradation by fatigue. However, with the 
recent demonstration of fatigue crack growth in ceramics, potential inelastic deformation mechanisms have been suggested $[20,21,27]$. Crack growth from mechanisms which damage the microstructure ahead of the crack-tip, as a result of the unloading cycle, have been suggested for ceramic materials. These mechanisms could involve crack extension by successive crack-tip blunting and resharpening (as in metals), or by the accumulation of shear or tensile cracking at the tip, resulting from the contact of fracture surfaces on unloading. Additionally, crack growth from mechanisms which do not necessarily differ from the crack advance mechanisms found in fracture from sustained loading, but enhance the crack driving force by reducing the crack tip shielding, have also been suggested for ceramic materials. Crack tip shielding is a toughening mechanism which serves to shield the crack tip from the full impact of the crack driving force, thereby increasing the fracture toughness and lowering the fatigue crack growth rates [29]. Possible mechanisms which reduce the crack-tip shielding include 1.) damaging of the crack bridging (where bridging is the retention of material ligaments across the fracture plane), 2.) damaging of the fracture surface wedging and interlocking asperities, 3.) degrading of the transformation toughening in transforming ceramics. The reduction in crack-tip shielding increases the near-tip stress intensity factor compared to sustained loading conditions. Because of the similarities between lithium hydride and ceramics (their propensity for brittle fracture and their low values of fracture toughness), many of these suggested fatigue mechanisms for ceramics, which damage the microstructure ahead of the crack-tip and increase the crack driving force, are potential mechanisms for subcritical fatigue crack growth in lithium hydride as well.

In view of the observed fatigue crack growth results, neglecting the fatigue effects in the design and life prediction of a lithium hydride component which is exposed to cyclical loading will result in an overestimate of the expected life. 


\section{Conclusions}

1. Subcritical fatigue crack growth, from cyclic tensile loading, was found to exist in warm pressed polycrystalline lithium hydride.

2. The fatigue crack growth was fourd to occur between $7.56 \times 10^{-11} \mathrm{~m} /$ cycle $\left(2.98 \times 10^{-9} \mathrm{in} / \mathrm{cycle}\right)$ and $2.35 \times 10^{-8} \mathrm{~m} /$ cycle $\left(9.24 \times 10^{-7} \mathrm{in} / \mathrm{cycle}\right)$ for a range of stress intensity factors of $1.04 \mathrm{MPa} \cdot \sqrt{\mathrm{m}}(0.95 \mathrm{ksi} \cdot \sqrt{\mathrm{in}})$ to $1.49 \mathrm{MPa} \cdot \sqrt{\mathrm{m}}(1.36 \mathrm{ksi} \cdot \sqrt{\mathrm{in}})$.

3. A cyclic fatigue crack growth behavior was demonstrated by a higher rate of crack growth in tension-tension cyclic loading as compared to the rate of crack growth from sustained loading (at an equivalent stress intensity factor).

4. A fatigue threshold was not evident from the acquired data. The range of stress intensity factors at a rate of fatigue crack growth of $\mathrm{da} / \mathrm{dN}=1.00 \times 10^{-10} \mathrm{~m} / \mathrm{cycle}$ $\left(3.94 \times 10^{-9} \mathrm{in} /\right.$ cycle $)$ was found to be $1.05 \mathrm{MPa} \cdot \sqrt{\mathrm{m}}(0.96 \mathrm{ksi} \cdot \sqrt{\mathrm{in}})$. 


\section{References}

1 T. Dalrymple (1988) Vibroimpact Code Validation - Analytical and Experimental Data (U). Lawrence Livermore National Laboratory Interdepartmental Memorandum, COMW-88-0670.

2 G.R. Irwin (1958) Fracture I. Handbauch der Physik VI, Springer, Berlin, Germany, 6, 558-590.

3 C.R. Hookham (1980) Use of Linear Elastic Fracture Mechanics in Estimating Fatigue Crack Growth Rates and Residual Strength of Components. Engineering Sciences Data Item, No. 80036.

4 A.A. Griffith (1924) The Theory of Rupture. Proc. First Int. Conf. on Applied Mech. 55.

5 A.A. Griffith (1921) The Phenomena of Rupture and Flow in Solids. Philosophical Transactions of the Royal Society of London A221, 163-198.

6 G.R. Irwin (1948) Fracture Dynamics. Fracturing of Metals, American Society for Metals, 147-166.

7 P.C. Paris (1964) Proc. 10th Sagamore Conf.. Syracuse University Press, Syracuse, N.Y., 107.

8 A.G. Evans (1980) Fatigue in Ceramics. Int. J. Fract. 16, 485-495.

9 A.G. Evans and E.R. Fuller (1974) Crack Propagation in Ceramic Materials under Cyclic Loading Conditions. Metall. Trans. 5, 27-33.

10 A.G. Evans, L.R. Russell, and D.W. Richerson (1975) Slow Crack Growth in Ceramic Materials at Elevated Temperatures. Metall. Trans. 6, 707-716.

11 A.G. Evans and M. Linzer (1976) High-Frequency Cyclic Crack Propagation in Ceramic Materials. Int. J. Fract. 12, 217-222.

12 S.M. Wiederhorn, E.R. Fuller, and R. Thomson (1980) Micromechanisms of Crack Growth in Ceramics and Glasses in Corrosive Environments. Met. Sci. 14, 450-458.

13 P.F. Becher (1986) Subcritical Crack Growth in Partially Stabilized $\mathrm{ZrO}_{2}(\mathrm{MgO})$. J. Mater. Sci. 21, 297-300.

14 L. Ewart and S. Suresh (1987) Crack Propagation in Ceramics under Cyclic Loads. J. Mater. Sci. 23, 1173-1192. 
15 S. Suresh and J.R. Brockenbrough (1988) Theory and Experiments of Fracture in Cyclic Compression: Single Phase Ceramics, Transforming Ceramics, and Ceramic Composites. Acta metall. 36, 1455-1470.

16 R.H. Dauskardt, E. Yu, and R.O. Ritchie (1987) Fatigue Crack Propagation in Transformation-Toughened Zirconia Ceramic. J. Am. Ceram. Soc. 70, C248-C252.

17 R.H. Dauskardt and R.O. Ritchie (1989) Cyclic Fatigue-Crack Growth Behavior in Ceramics. MTS Closed Loop, 7-17.

18 J. Tsai, C. Yu, and D.K. Shetty (1990) Fatigue Crack Propagation in Ceria-PartiallyStabilized Zirconia (Ce-TZP)-Alumina Composites. J. Am. Ceram. Soc. 73, 29923001 .

19 R.H. Dauskardt, D.B. Marshall, R.O. Ritchie (1990) Cyclic Fatigue-Crack Propagation in Magnesia-Partially-Stabilized Zirconia Ceramics. J. Am. Ceram. Soc. 73, 893-903.

20 R.O. Ritchie and R.H. Dauskardt (1991) Cyclic Fatigue of Ceramics: A Fracture Mechanics Approach to Subcritical Crack Growth and Life Prediction. J. Ceram. Soc. Jap. 99, 1047-1062.

21 R.O. Ritchie, R.H. Dauskardt, and Weikang Yu (1990) Cyclic Fatigue-Crack Propagation, Stress-Corrosion, and Fracture-Toughness Behavior in Pyrolytic Carbon-Coated Graphite for Prosthetic Heart Valve Applications. J. Biomed. Res. 24, 189-206.

22. R. Baylor Jr., T.R. Harvey, J.D. Kennedy, J.H. Leckey, M.J. Marsicek, J.F. McLaughlin, R.E. Oakes Jr., L.E. Pender, and D.A. Waldrop (1990) Properties of Warm-Pressed Lithium Hydride/Deuteride. Oak Ridge Y-12 Plant Document, No. Y/DZ-578.

23 D.A. Waldrop, M.J. Marsicek, and K.C. Liu (1992) Design and Evaluation of a Uniaxial Pull Test for Lithium Hydride/Deuteride. Oak Ridge Y-12 Plant Document, No. Y-2447.

24 R.E. Oakes Jr. (1991) Specimen Type and Size Effects on Lithium Hydride Tensile Strength Distributions. Oak Ridge Y-12 Plant Document, No. Y-2440.

25 C.L. Hoenig, R.L. Landingham, T.E. Shell, and S.C. Aceves (1987) Fracture Toughness and Compressive Strength of $\mathrm{LiH}(\mathrm{U})$. Lawrence Livermore National Laboratory, COCDA-87-006.

26 ASTM designation E647-91 (1991) Standard Test Method for Measurement of Fatigue Crack Growth Rates. American Society for Testing and Materials, Philadelphia, $\mathrm{Pa}$. 
27 S.Suresh (1991) Fatigue Crack Growth in Brittle Materials. J. Hard Mater. 2, 29-54.

28 D. Broek (1991) Elementary Engineering Fracture Mechanics. Kluwer Academic Publishers, Dordrecht, 27.

29 R.W. Hertzberg (1989) Deformation and Fracture Mechanics of Engineering Materials. John Wiley \& Sons, 356. 


\section{Appendix A - Crack Extension Stability}

Crack extension stability, as discussed by Sakai and Inagaki [30], was used to determine the appropriate length of the machined portion of the crack in the test specimen. The machined crack was determined such that, for the calculated specimen compliance and the measured test machine axial compliance, an increase in the total energy of the system would be required for further crack extension in equilibrium. In other words, to provide for "stable" crack growth, an equilibrium fracture must exist where the potential energy release rate of the test system is balanced with the intrinsic fracture energy. For a specimen compliance which is too low relative to the axial compliance of the test machine (i.e. too stiff of a specimen or not a stiff enough test machine), the excessive system energy could result in crack growth instability. Sakai and Inagaki say that at crack initiation and during quasi-static extension in equilibrium fracture, the total energy $\left(G_{e q}\right)$ of a linear elastic system comprising a specimen and a testing machine can be described in terms of the elastic stored energy of the specimen and testing machine $\left(U_{e}\right.$ and $\left.U_{m}\right)$, the fracture surface energy $\left(\gamma_{s}\right)$, the fracture surface area $(A)$ and its initial value $\left(A_{0}\right)$ as follows:

$$
\mathrm{G}_{e q}(\mathrm{a})=\mathrm{U}_{\mathrm{e}}+\mathrm{U}_{\mathrm{m}}+2 \gamma_{\mathrm{s}}\left(\mathrm{A}-\mathrm{A}_{\mathrm{o}}\right)
$$

The stability in equilibrium fracture is controlled by the sign of the second derivative of the system energy. Accordingly, the required compliance of the test specimen, for a measured test machine axial compliance, is determined by evaluating the energy for which an increase in energy is required for further crack extension $\left(\partial^{2} \mathrm{G} / \partial \mathrm{a}^{2}>0\right)$.

30 Mototsugu Sakai and Michio Inagaki (1989) Dimensionless Load-Displacement Relation and Its Application to Crack Propagation Problems. J. Am. Ceram. Soc. 72, 388-394. 


\section{Appendix B - Test Apparatus}

The electro-servo-hydraulic test system incorporated an MTS model 300.03 hydraulic load frame connected to a $20.7 \mathrm{MPa}$ (3000 psi) hydraulic power supply through a Moog model A076-260C, $6.309 \mathrm{E}-5 \mathrm{~m}^{3} / \mathrm{sec}$ (1 GPM), servo valve.

The controller for the load frame was an MTS model 458.20 MicroConsole, a model 458.11 DC controller, and two model 458.13 AC controllers. A Program command signal to the controller was provided by an MTS model 458.91 MicroProfiler.

A CrackWatch computer control system and an IBM 386 PC were in series between the MicroProfiler and the controller. The CrackWatch system incorporated a Data Translation model DT2838 board to digitize the analog load and displacement signals. The computer control system provided automatic modification of the control parameter signal to accommodate stress intensity control. Also, the CrackWatch system was used to continuously reduce and record the load, strain, and crack length data. The CrackWatch system was manufactured by Interactive Software Controls located in Berkeley, California.

The loading fixtures incorporated a clevis and pin assembly at the top and bottom of the specimen to allow in-plane rotation as the specimen was loaded. Heim spherical bearings model LHSSE-16 were used at the top and the bottom of the load train to assure loading symmetry. Boston Gear model B1620-6 sintered bronze bearings, coated with molybdenum disulfide, were used within the clevis to minimize the influence of the pin to clevis interface friction.

The crack mouth opening displacement was measured with a Schaevitz model LBB315PA-020 Linear Variable Differential Transformer (LVDT). The LVDT is rated at $\pm 0.508 \mathrm{~mm}( \pm 0.020 \mathrm{inch})$ with an output of $275.6 \mathrm{mV} / \mathrm{V} / \mathrm{mm}(7.0 \mathrm{mV} / \mathrm{V} / \mathrm{mil})$. The excitation for the LVDT was $5.0 \mathrm{~V}_{\mathrm{rms}}$ at $10 \mathrm{kHz}$ provided by an MTS model $458.13 \mathrm{AC}$ controller. The range card corresponding to a full scale range of $\pm 0.254 \mathrm{~mm}( \pm 10$ mils) was used providing a displacement measurement resolution of $0.001 \mathrm{~mm}(0.05$ mils $)$. The 
LVDT was staticly calibrated with a Boeckeler Head model 1398 linear displacement device within an accuracy of $1.34 \%$ of the reading.

The load placed on the test unit was measured with an Interface 1010 strain gauged load cell. The load cell was rated at $4448 \mathrm{~N}(1000 \mathrm{lb}$.) full scale with an output of $1 \mathrm{mV} / \mathrm{V}$. The excitation for the load cell was 10 VDC provided by a MTS model $458.11 \mathrm{DC}$ Controller. A smaller load cell would provide a more desirable signal to noise ratio, but would result in an unacceptable reduction in axial stiffness. The range card corresponding to a full scale range of $\pm 889.6 \mathrm{~N}$ ( $\pm 200 \mathrm{lb}$.) was used providing a load measurement resolution of $4.45 \mathrm{~N}(1 \mathrm{lb}$.). The load cell was staticly calibrated in place within an accuracy of $0.97 \%$ of the reading.

The argon which purged the test unit environmental enclosure was passed through a moisture trap, oxygen trap, and hydrocarbon trap to remove contaminants. The gas purifier was a Multi-Purge II model manufactured by Alltech. The argon exited the environmental enclosure through a High Efficiency Sample Line Filter to trap Lithium hydride (in the unlikely event that Lithium hydride becomes airborne). The filter was a type B in-line filter manufactured by MSA Instruments. 
Appendix C - Fatigue Crack Growth Data

\begin{tabular}{|c|c|}
\hline $\begin{array}{c}\text { Range of Stress Intensity Factors } \\
M P a \cdot \sqrt{\mathrm{m}}(\mathrm{ksi} \cdot \sqrt{\mathrm{in}})\end{array}$ & $\begin{array}{c}\text { Fatigue Crack Growth Rate } \\
\mathrm{m} / \text { cycle (in/cycle) }\end{array}$ \\
\hline \multicolumn{2}{|c|}{$\begin{array}{ll}\text { Specimen No. } 1 \\
\end{array}$} \\
\hline $1.471(1.338)$ & $1.55 \mathrm{E}-08 \quad(6.12 \mathrm{E}-07)$ \\
\hline $1.473(1.340)$ & $1.39 \mathrm{E}-08 \quad(5.46 \mathrm{E}-07)$ \\
\hline $1.475(1.342)$ & $1.52 \mathrm{E}-08 \quad(5.97 \mathrm{E}-07)$ \\
\hline $1.476(1.343)$ & $1.46 \mathrm{E}-08 \quad(5.75 \mathrm{E}-07)$ \\
\hline $1.478 \quad(1.345)$ & $1.18 \mathrm{E}-08 \quad(4.64 \mathrm{E}-07)$ \\
\hline $1.480 \quad(1.347)$ & $9.17 \mathrm{E}-09 \quad(3.61 \mathrm{E}-07)$ \\
\hline $1.482(1.349)$ & $1.05 \mathrm{E}-08 \quad(4.13 \mathrm{E}-07)$ \\
\hline $1.484 \quad(1.351)$ & $9.71 \mathrm{E}-09 \quad(3.82 \mathrm{E}-07)$ \\
\hline $1.486(1.353)$ & $8.09 \mathrm{E}-09 \quad(3.19 \mathrm{E}-07)$ \\
\hline $1.488 \quad(1.355)$ & $1.08 \mathrm{E}-08 \quad(4.26 \mathrm{E}-07)$ \\
\hline $1.491 \quad(1.357)$ & $2.35 \mathrm{E}-08 \quad(9.24 \mathrm{E}-07)$ \\
\hline \multicolumn{2}{|c|}{ Specimen No. 2} \\
\hline $1.040(0.947)$ & $7.56 \mathrm{E}-11 \quad(2.98 \mathrm{E}-09)$ \\
\hline $1.126(1.025)$ & $1.68 \mathrm{E}-10 \quad(6.60 \mathrm{E}-09)$ \\
\hline $1.123(1.022)$ & $3.50 \mathrm{E}-10 \quad(1.38 \mathrm{E}-08)$ \\
\hline $1.217(1.107)$ & $2.02 \mathrm{E}-10 \quad(7.94 \mathrm{E}-09)$ \\
\hline $1.213(1.104)$ & $2.67 \mathrm{E}-10 \quad(1.05 \mathrm{E}-08)$ \\
\hline $1.322(1.203)$ & $3.90 \mathrm{E}-10 \quad(1.53 \mathrm{E}-08)$ \\
\hline $1.319(1.200)$ & $1.17 \mathrm{E}-09 \quad(4.60 \mathrm{E}-08)$ \\
\hline
\end{tabular}

